\title{
Medical role of first responders in an urban prehospital setting
}

\author{
Ross Berringer, MD;* Jim Christenson, MD;* Maurice Blitz, MD; † John Spinelli, PhD; \\ Jeff Freeman, MD;§ Glenn Maddess;đI Sandra Rae, MSc $\neq$
}

\begin{abstract}
:
Background: Almost all North American cities have first responder programs. To date there is no published documentation of the roles first responders play, nor of the frequency and type of interventions they perform. Many urban stakeholders question the utility and safety of routinely dispatching large vehicles emergently to calls that may not require their services. Real world data on first responder interventions will help emergency medical services (EMS) directors and planners determine manpower requirements, assess training needs, and optimize dispatch protocols to reduce the rate of inappropriate "code 3 " (lights and siren) responses.

Objective: Our objectives were to determine how often first responders arrive first on scene, to estimate the time interval between first response and EMS response, and to examine the frequency and type of interventions performed by first responders.

Methods: In a prospective observational study, trained observers were assigned to fire department first responder (FDFR) units. These observers recorded on-scene times for FDFR and EMS units, and documented the performance of first responder interventions.

Results: FDFRs arrived first on scene in $49 \%$ of code 3 calls. They performed critical interventions in $18 \%$ of calls attended and $36 \%$ of calls where they arrived first. Oxygen administration was the most frequent critical intervention, yet occult hypoxemia was common and compliance with oxygen administration protocols was poor.

Conclusions: First responders perform critical interventions during a minority of code 3 calls, even when "critical" is defined generously. Many "lights and siren" dispatches are unnecessary. Future research should attempt to identify dispatch criteria that more accurately predict the need for first responder intervention. First responder training and continuous quality improvement (CQI) should focus on interventions that are performed with some regularity, particularly oxygen administration.
\end{abstract}

\section{RÉSUMÉ ANALYTIQUE :}

Historique : Pratiquement toutes les villes d'Amérique du Nord possèdent un programme d'intervention d'urgence. Jusqu'à maintenant, il n'existe aucune documentation publiée quant aux rôles de ces intervenants, ni à la fréquence et au type d'interventions qu'ils effectuent. Plusieurs dépositaires d'enjeux en milieu urbain mettent en doute l'utilité et la sécurité de l'envoi d'urgence de véhicules lourds pour répondre à des appels où leurs services ne seront peut-être pas requis. Des données concrètes quant aux actes des premiers intervenants aideront les directeurs et les planificateurs des services médicaux à déterminer les besoins en main-d'oeuvre, à évaluer les besoins de formation et à optimiser les protocoles de répartition afin de réduire le taux de réponses «code 3» inutiles (lumières et sirène).

Objectif : Nos objectifs étaient de déterminer à quelle fréquence les intervenants d’urgence arrivaient les premiers sur les lieux de l'incident, d'estimer l'intervalle entre la première intervention et celle des $S M U$, et d'examiner la fréquence et le type d'interventions effectuées par les premiers intervenants.

\footnotetext{
*Department of Emergency Medicine, St. Paul’s Hospital, Vancouver, BC; †University of Alberta, Edmonton, Alta.; $\ddagger$ Centre for Health Evaluation and Outcome Studies (CHEOS), Vancouver, BC; §Department of Emergency Medicine, Royal Columbian Hospital, New Westminster, BC; \Chief, Vancouver Fire and Rescue Service, Vancouver, BC

This article has been peer reviewed.
} 
Méthodes : Lors d'une étude prospective, des observateurs qualifiés furent assignés aux unités $d^{\prime}$ intervention d'urgence du département des incendies (IUDI). Ces observateurs notèrent le délai d'arrivée sur les lieux de l'incident pour les unités de IUDI et de SMU et documentèrent la performance des premières interventions.

Résultats: Les unités de IUDI arrivèrent les premières sur les lieux de l'incident dans $49 \%$ des appels code 3 . Elles effectuèrent des interventions critiques dans $18 \%$ des appels auxquels elles participèrent et dans $36 \%$ des appels lorsqu'elles arrivèrent les premières. L'administration d'oxygène constituait l'intervention critique la plus fréquente. Or, I'hypoxémie occulte était courante et le respect du protocole d'administration de l'oxygène était inadéquat.

Conclusions: Les premiers intervenants effectuent des interventions critiques pour une minorité d'appels code 3, même lorsqu'on utilise le terme «critique» au sens large. Plusieurs répartitions accompagnées de lumières et de sirènes sont inutiles. Les recherches futures devraient tenter d'identifier les critères de répartition qui prédisent le plus fidèlement le besoin d'une intervention d'urgence. La formation des premiers intervenants et l'amélioration continue de la qualité devraient cibler les interventions effectuées sur une base régulière comme l'administration d'oxygène.

Key words: first responder, emergency medical systems, emergency medical technician, allied health personnel, emergencies, prehospital care, health care delivery, time factors.

\section{Introduction}

The previous two decades have witnessed a proliferation of Emergency Medical Systems (EMSs) with an increased ability to provide sophisticated on-scene care. This growth may be driven not only by public need but by agency-specific agendas. Over the last 10 years, first responder programs have experienced parallel growth. In 1990, an estimated $96 \%$ of US cities had first responder programs, although the deployment and utilization of these resources varied substantially. ${ }^{1,2}$

First responders, usually fire or police units, are typically activated simultaneously with ambulance personnel. At the time of this study in Vancouver, British Columbia, fire department first responders (FDFR) were dispatched code 3 (lights and siren) in 54\% of cases (Drew Burgwin, Quality Assurance Manager, British Columbia Ambulance Service, Vancouver, BC: personal communication, 1998). Many urban stakeholders question the utility and safety of routinely dispatching large vehicles emergently to calls that may not require their services.

At present there is no published documentation of the roles of first responders, nor of the type and frequency of interventions they perform in urban settings. Given that the average interval between first responder and ambulance arrival is only three minutes, it is important to determine the frequency of critical interventions performed prior to the arrival of more definitive care. ${ }^{2}$ In addition, a description of non-critical first-responder functions, such as extrication, hazardous material containment, and crowd control, is warranted. Real world data on first responder interventions will help EMS directors and planners determine manpower requirements, assess training needs, develop treatment protocols, and perhaps reduce the rate of inappropriate "code 3 " responses.

Our objectives were to determine how often first responders arrive first, to estimate the time interval between first response and EMS response, and to examine the frequency and type of interventions performed by first responders.

\section{Methods}

This prospective survey of urban first responder interventions was performed as part of a larger study looking at the potential impact of new dispatch protocols. Ethics approval for the study was received from the University of British Columbia Clinical Screening Committee for Research Involving Human Subjects.

\section{Setting}

Vancouver, BC, is an urban centre covering 113 square kilometers with a population of 546,000. Residents are serviced by a single ambulance provider, the British Columbia Ambulance Service (BCAS), which is the EMS agency charged with providing prehospital care to all residents of the province. BCAS personnel are trained to an Emergency Medical Technician-I (EMT-I), EMT-II, or EMT-Paramedic (EMT-P) level. Ambulance personnel within Vancouver are distributed amongst 11 ambulance stations, two which are EMT-Paramedic staffed. First responder resources are provided by Vancouver Fire and Rescue Service (VFRS), who maintain 20 fire halls within the city and respond to approximately 27,000 medical calls per year. All members of 
VFRS are trained for 32 hours in first responder skills and 16 hours in automated external defibrillator (AED) and spinal immobilization techniques.

At the time of the study, medical emergency calls were routed through a central 911 agency to a physically separate ambulance dispatch centre, where an ambulance dispatcher designated each call as code 2 (routine) or code 3 (lights and siren). On all code 3 calls the dispatcher notified the closest available ambulance crew, then contacted the Fire Department dispatch centre with the nature and location of the call. Fire dispatch relayed calls to the closest fire hall and dispatched an engine or ladder truck in first response.

\section{Data collection and management}

To investigate the role of first responders, 4 study observers were stationed in 5 busy firehalls. The observers, second or third year medical students trained in data collection and pulse oximetry, worked five 12-hour shifts per week, usually from 14:00 to 02:00. During these shifts they accompanied VFRS first responders on all medical calls, completed standard data collection forms, and performed pulse oximetry on patients being treated. They were instructed not to collect oximetry data if it delayed the treatment of critical patients or if it placed them in a position of risk. For study purposes, an oxygen saturation $\left(\mathrm{SpO}_{2}\right)$ greater than or equal to $95 \%$ was designated as adequate oxygenation.

Study observers synchronized their timers with VFRS dispatch prior to each shift and recorded all pertinent times to the nearest minute. Data included VFRS dispatch time, time at scene, time at patient's side, time of BCAS arrival, vital signs, field diagnosis, intervention performed, and $\mathrm{SpO}_{2}$ prior to initiation of treatment.

\section{First responder interventions}

First responder interventions were classified as primary critical, secondary critical, and non-critical. Primary critical interventions are interventions with the potential to improve patient outcome during the 1- to 3-minute delay to paramedic arrival. Secondary critical interventions are useful but less time-dependent and less likely to directly improve patient outcomes. Non-critical interventions are other activities carried out by first responders. Because of the lack of previous research addressing first responder interventions, these definitions were established by consensus prior to the study by the investigators and the BCAS Medical Advisory Committee.

Primary critical interventions included oxygen administration (when $\mathrm{SpO}_{2}<95 \%$ ), airway manoeuvre, airway suction, airway insertion, assisted ventilation, CPR, AED use, and bleeding control. Secondary critical interventions included oxygen administration (when $\mathrm{SpO}_{2}>95 \%$ ), oral glucose administration, extrication, fire suppression, hazardous material containment, crowd and traffic control, and locating the patient. Non-critical interventions included patient positioning, splinting, spinal immobilization, provision of a verbal or written report, and assisting BCAS with transport.

Clerical staff double-entered all data into a standard spreadsheet. To ensure accurate data entry, any discrepancies were clarified using source documents. Descriptive statistics, including means, medians, and standard deviations were calculated where appropriate.

\section{Results}

During the study period, observers attended 743 code 3 calls. In $362(49 \%)$ of these, VFRS first responders arrived first. In 255 cases (34\%), BCAS personnel arrived first and declined VFRS assistance. In 98 cases (13\%), BCAS personnel arrived first and requested VFRS assistance. In 28 calls (4\%), most often related to cardiac arrest, a second VFRS unit was called in to provide assistance. Our primary interest was in the 49\% of calls where VFRS personnel were first on scene. Unless otherwise noted, the following data refer to this subset of calls.

In this group, the median time interval from call receipt to VFRS arrival at scene was 2 minutes (range $0-12, n=$ 361) and median time to the initiation of first responder interventions was 1 minute. The median time to BCAS arrival was 5 minutes (range $1-14, n=347$ ), and the time interval from arrival at scene to patient's side was 1 minute (range 0-3, $n=299$ ).

Table 1 summarizes demographics and clinical parameters from 366 patients treated by first responders during 362 calls. Most patients were male, and the mean age was 40 . Study observers were not permitted to examine patients or measure vital signs; therefore, data was recorded as "missing" if first responders failed to convey them to observers.

Table 1. Characteristics of 366 patients in 362 calls where Vancouver Fire and Rescue Service (VFRS) arrived before emergency medical services

\begin{tabular}{lcc} 
& $\begin{array}{c}\text { Patient } \\
\text { characteristics }\end{array}$ & Data missing $(n)$ \\
\hline Male/female & $257 / 103$ & 6 \\
Mean age & & \\
$\quad$ standard deviation [SD]) & $40(18)$ & 7 \\
Mean pulse (SD) & $98(25)$ & 46 \\
Mean respiratory rate (SD) & $18(10)$ & 90 \\
Mean Glascow Coma Score (SD) & $13(2)$ & 19 \\
Evidence of blood at scene: $n$ (\%) & $110(30)$ & 14 \\
Mean oxygen saturation (SD) & $88(12)$ & 72 \\
Oxygen given prior to & $148(40)$ & 0 \\
$\quad$ BCAS arrival: $n$ (\%) & &
\end{tabular}

BCAS = British Columbia Ambulance Service 
Table 2 summarizes the field diagnoses and pulse oximetry data collected for the 366 eligible patients. The most common field diagnosis was drug or alcohol overdose (34\%), followed by shortness of breath (8\%), collapse or found down (7\%), motor vehicle accident (7\%), and seizures (7\%).

Table 3 shows that oxygen administration was the most frequent critical intervention $(n=148)$. Oxygen saturation data was collected from 294 of 366 eligible patients. Reasons for failure to collect oxygen saturation included, in order of frequency: poor correlation to pulse, difficulty accessing patient, lack of cooperation, and pediatric patients. Of the 294 patients with saturation data, 128 were relatively hypoxemic $\left(\mathrm{SpO}_{2}<95 \%\right)$. In this group, only 86 patients $(67 \%)$ were given oxygen, while $62(37 \%)$ of 166 patients with normal saturations were given oxygen.

Table 4 shows that, when they arrived first on scene, first responders performed a primary or secondary critical intervention during 212 calls (59\%). This figure falls to 133 calls $(37 \%)$ if only primary critical interventions are considered.

\section{Discussion}

Existing studies suggest that EMT-P interventions are performed during $5 \%$ to $20 \%$ of code 3 calls..$^{3-6}$ However, outside the setting of cardiac arrest, ${ }^{7-10}$ there are no peer- reviewed publications dealing with the medical roles of first responders. Given this relative vacuum of information, we attempted to acquire descriptive data defining the role first responders play in urban prehospital care.

In this study, first responders arrived first in only $49 \%$ of calls. This is surprising, given the fact that Vancouver has half as many ambulance stations as fire halls, and is one reason why first responder impact is limited. Several factors may contribute to this. First, ambulance crews are more likely to be on the road than in the hall, thus eliminating the 30 to 60 second roll-out period. Second, the dispatch centre was staffed by ambulance personnel, who may have dispatched their own units prior to the fire company. A dispatch system with simultaneous fire and ambulance notification might increase the proportion of calls where FDFRs arrive first. FDFR impact was also limited by the fact that, when BCAS arrived first, they declined first responder assistance in $72 \%$ of cases, perhaps reflecting a degree of professional rivalry that exists between the two services.

In this study, the most common "critical" first responder interventions were oxygen administration, crowd and traffic control, bleeding control, airway manoeuvres, and airway insertion (Table 3); however, during the 9-week study, first responders performed primary critical interventions (corrected for oxygen saturation) during only 133 (37\%) of

\begin{tabular}{|c|c|c|c|c|c|c|}
\hline Field diagnosis & $n=366$ & $\%$ of total & $\begin{array}{l}\text { No. with } \\
\text { oximetry }\end{array}$ & $\begin{array}{l}\text { Median } \mathrm{O}_{2} \\
\text { saturation }\end{array}$ & Range & $\begin{array}{c}\% \text { given } \mathrm{O}_{2} \\
\text { by VFRS }\end{array}$ \\
\hline Drug/alcohol overdose & 125 & 34.3 & 104 & 91 & $(19-100)$ & 38 \\
\hline Respiratory / shortness of breath & 30 & 8.2 & 26 & 93.5 & $(78-99)$ & 67 \\
\hline Collapse & 27 & 7.4 & 20 & 95.5 & (89-99) & 22 \\
\hline Motor vehicle accident & 25 & 6.9 & 18 & 98 & $(97-100)$ & 8 \\
\hline Seizure & 25 & 6.9 & 23 & 93 & $(86-99)$ & 60 \\
\hline Trauma, minor & 20 & 5.5 & 15 & 96 & $(92-99)$ & 15 \\
\hline Head injury & 18 & 4.9 & 13 & 97 & $(92-99)$ & 22 \\
\hline Other & 18 & 4.9 & 9 & 98 & $(95-99)$ & 33 \\
\hline Violence & 15 & 4.1 & 14 & 95.5 & $(92-99)$ & 13 \\
\hline Chest pain, other & 12 & 3.3 & 12 & 97.5 & $(95-99)$ & 83 \\
\hline Trauma, major & 10 & 2.7 & 7 & 96 & $(90-97)$ & 80 \\
\hline Psychiatric & 8 & 2.2 & 7 & 96 & $(95-99)$ & 25 \\
\hline Fracture & 6 & 1.6 & 6 & 97.5 & $(96-99)$ & 33 \\
\hline Hemorrhage & 5 & 1.4 & 4 & 95 & $(86-98)$ & 20 \\
\hline Chest pain / myocardial infarction & 3 & 0.8 & 3 & 98 & (94-99) & 100 \\
\hline Chronic disorder & 3 & 0.8 & 3 & 91 & $(86-97)$ & 33 \\
\hline Diabetes & 3 & 0.8 & 2 & 96.5 & $(93-100)$ & 100 \\
\hline Dead on arrival & 3 & 0.8 & 0 & & & \\
\hline Abdominal pain & 3 & 0.8 & 2 & 97 & $(85-98)$ & 33 \\
\hline Airway obstruction & 2 & 0.5 & 2 & 97 & $(96-98)$ & 0 \\
\hline Cardiac arrest & 2 & 0.5 & 0 & & & 100 \\
\hline Neurologic / cardiovascular accident & 1 & 0.5 & 2 & 94 & $(91-97)$ & 50 \\
\hline Burns & 1 & 0.3 & 1 & 96 & & 100 \\
\hline Infectious disease & 1 & 0.3 & 0 & & & \\
\hline
\end{tabular}


362 calls when they arrived first on scene, or $18 \%$ of the 743 code 3 calls studied.

Given the relative infrequency of critical first responder interventions seen in this study, it seems an unnecessary and potentially dangerous duplication of services to routinely dispatch both a fire apparatus and an ambulance code 3, only to have first responders render no necessary services in the majority of cases, although there may be a subset of calls where illness severity (e.g., cardiac arrest) justifies a dual response. The brevity of the interval between first responder and ambulance arrival, the infrequency of critical first responder interventions, and the time and cost required for training and maintenance of competence argue against extensive training of first responders in advanced medical protocols.

\section{Pulse oximetry and oxygen utilization}

Based on the work of other investigators, ${ }^{11}$ we defined $95 \%$ as an adequate oxygen saturation. By this definition, 128 of 294 patients with oxygen saturation data were hypoxemic. Interestingly, oxygen was administered to 62 (35\%) of 166 patients who were not hypoxemic and to only $86(67 \%)$ of those who were. Despite the fact that oxygen is mandated in the treatment protocols for many of these patients, a substantial proportion did not receive it, and we found an alarmingly high incidence of occult hypoxemia in overdose and seizure patients (Table 2).

In a previous paper, Cydulka and colleagues suggested that prehospital oximetry could decrease oxygen utilization by $60 \% .{ }^{11}$ In our study, oxygen was administered "inappropriately" to 62 patients and was withheld inappropriately from 42 patients; therefore, while prehospital oximetry might reduce inappropriate oxygen administration, this effect would be balanced by increases in appropriate utilization. The net effect would be more "accurate" oxygen administration - a worthy goal — but potential cost savings would be limited.

\section{Limitations}

We attempted to acquire data on a representative sample of code 3 first responder calls, but the distribution of our field diagnoses suggests we may not have accomplished this. Three diagnostic categories - overdose, collapse, and seizure - constituted $49 \%$ of all calls. This probably occurred because the busiest two fire halls in our study were in close proximity to the downtown east side of Vancouver, an area whose population has a high incidence of drug and alcohol abuse. The disproportionate rate of "substance abuse" calls likely inflated the number of "critical interven- tions" performed, since these patients often require airway manoeuvres or oxygen administration. Our results are, therefore, most generalizable to urban inner city settings and less generalizable to suburban or rural EMS systems.

The study may also have been biased by the fact that our observers collected most data between 14:00 and 02:00.

Table 3. First responder interventions performed during 362 calls

$n \quad \%$ of calls

\begin{tabular}{|c|c|c|}
\hline \multicolumn{3}{|l|}{ Primary critical intervention } \\
\hline Oxygen administered (saturation $<95 \%$ ) & 90 & 25 \\
\hline Bleeding control & 38 & 10.5 \\
\hline Airway manoeuvre & 38 & 10.5 \\
\hline Airway inserted & 37 & 10.2 \\
\hline Assisted ventilation & 36 & 10 \\
\hline Airway suction & 3 & 0.8 \\
\hline $\begin{array}{l}\text { Cardiopulmonary resuscitation } \\
\text { (CPR) started }\end{array}$ & 3 & 0.8 \\
\hline Automated external defibrillator used & 1 & 0.3 \\
\hline \multicolumn{3}{|l|}{ Secondary critical intervention } \\
\hline Oxygen administered (saturation $>95 \%$ ) & 58 & 16 \\
\hline Crowd/traffic/safety & 38 & 10.5 \\
\hline Search for patient & 9 & 2.5 \\
\hline Extrication/access & 5 & 1.4 \\
\hline Oral glucose given & 2 & 0.5 \\
\hline Fire suppression & 0 & 0.0 \\
\hline 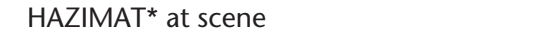 & 1 & 0.3 \\
\hline \multicolumn{3}{|l|}{ Non-critical intervention } \\
\hline Gloves worn & 316 & 87 \\
\hline Report to BCAS & 269 & 74 \\
\hline Patient positioned & 220 & 61 \\
\hline Vitals recorded & 152 & 42 \\
\hline Assist with BCAS equipment & 126 & 35 \\
\hline Assist with moving patient & 109 & 30 \\
\hline Cervical immobilization & 27 & 7.4 \\
\hline Assist with CPR/ventilation & 27 & 7.5 \\
\hline Injury splinted & 3 & 0.8 \\
\hline Assist with transport to hospital & 2 & 0.5 \\
\hline
\end{tabular}

*HAZIMAT = hazardous materials.

Table 4. Interventions performed when fire department first responder arrived first $(n=362)$

\begin{tabular}{|c|c|c|c|}
\hline \multirow{2}{*}{$\begin{array}{l}\text { Interventions } \\
\text { performed per } \\
\text { call }(n)\end{array}$} & \multicolumn{3}{|c|}{ No. of calls (\%) } \\
\hline & $\begin{array}{l}\text { Primary critical } \\
\text { intervention }\end{array}$ & $\begin{array}{l}\text { Primary or secondary } \\
\text { critical intervention }\end{array}$ & $\begin{array}{l}\text { Non-critical } \\
\text { intervention }\end{array}$ \\
\hline 0 & $229(63.3)$ & $150(41.4)$ & $29 \quad(8.0)$ \\
\hline 1 & $90(24.9)$ & $145(40.1)$ & $21 \quad(5.8)$ \\
\hline 2 & $9 \quad(2.5)$ & $29 \quad(8.0)$ & $46(12.7)$ \\
\hline 3 & $2(0.6)$ & $4 \quad(1.1)$ & $53(14.6)$ \\
\hline 4 & $28 \quad(7.7)$ & $28 \quad(7.7)$ & 49 (13.5) \\
\hline 5 & $4 \quad(1.1)$ & $5 \quad(1.4)$ & $93(25.7)$ \\
\hline$>5$ & $0 \quad(0.0)$ & $1 \quad(0.3)$ & 71 (19.6) \\
\hline $\begin{array}{l}\text { Calls }(n) \text { with } \\
\geq 1 \text { intervention }\end{array}$ & $133(36.7)$ & $212(58.5)$ & $333(92.0)$ \\
\hline
\end{tabular}


This interval represents the busiest FDFR call period; it was chosen to maximize study efficiency, but it may also have influenced the type of patient seen.

This study overestimates the rate of critical interventions. Actions like oxygen administration, airway manoeuvre, airway insertion, and bleeding control were considered "critical," but in reality, it is not clear that these or other first responder interventions actually improve patient outcomes. While we defined several interventions as critical, the only first responder intervention shown to be effective is defibrillation. ${ }^{7-10,12}$

Because first responders knew they were being studied, the Hawthorne effect may have come into play. Perhaps, outside the study framework, first responders perform even fewer interventions. In spite of the above biases, which would lead us to overvalue first responders, our study suggests that first responders usually do not perform critical interventions, although this may not be the case in suburban or rural EMS systems where ambulance response times are longer.

Future studies should address the question of which, if any, first responder interventions improve patient outcomes and should attempt to identify the sub-group of calls that justify dual (fire and ambulance) code 3 response.

\section{Conclusions}

First responders perform critical interventions during a minority of code 3 calls, even when "critical" is defined in extremely generous fashion. Many "lights and siren" dispatches are unnecessary. Future research should attempt to identify dispatch criteria that more accurately predict the need for first responder intervention. First responder training and CQI should focus on interventions that are performed with some regularity, particularly oxygen administration.

\footnotetext{
Acknowledgements: This study was supported by a grant from the British Columbia Health Research Foundation (BCHRF). The authors wish to thank the Vancouver firefighters, BCAS ambulance personnel, Roxon Medical for the study oximeters, and Lorna McCreath from the City of Vancouver Human Relations Department.
}

\section{References}

1. Braun O, McCallion R, Fazackerley J. Necessity for objective analysis of EMS systems. Ann Emerg Med 1988;17:415-20.

2. Braun O, McCallion R, Fazackerley J. Characteristics of midsized urban EMS systems. Ann Emerg Med 1990;19:536-46.

3. McManus WF, Tresch DD, Darin JC. An effective prehospital emergency system. J Trauma 1977;17:304-10.

4. Pepe PE, Fischer RP, Mattox KL. Geographic patterns of urban trauma according to mechanism and severity of injury. J Trauma 1990;30:1125-32.

5. Pepe PE, Bass RR, Matsumoto CM. EMS call history within a large urban system. Geographical demands for basic and advanced life support and the implications for program planning [abstract]. Ann Emerg Med 1988;17:409-10.

6. Eaton D, Daskin D. Determining emergency medical service vehicle deployment in Austin, Texas. Interfaces 1985;15:96-108.

7. Hoekstra JW, Banks JR, Martin DR, Cummins RO, Pepe PE, Stueven HA, et al. Effect of first responder defibrillation on time to therapeutic interventions during out of hospital cardiac arrest. Ann Emerg Med 1993;22:1247-53.

8. Shuster MI, Keller JL. Effect of fire department first responder automated defibrillation. Ann Emerg Med 1993;22:721-7.

9. White RD, Asplin BR, Bugliosi TR. High discharge survival rate after out of hospital ventricular fibrillation with rapid defibrillation by police and paramedics. Ann Emerg Med 1996;28:480-5.

10. Callaham MC, Madsen CD. Relationship of timeliness of paramedic advanced life support interventions to outcome in out of hospital cardiac arrest treated by first responders with defibrillators. Ann Emerg Med 1996;27:638-48.

11. Cydulka RK, Shade B, Emerman CL, Gershman H, Kubincanek J, Gershman H. Prehospital pulse oximetry: Useful or misused? Ann Emerg Med 1992;27:675-9.

12. Callaham M. Quantifying the scanty science of prehospital emergency care. Ann Emerg Med 1997;30:785-90.

Correspondence to: Dr. Ross Berringer, St. Paul's Hospital, 1081 Burrard St., Vancouver BC V6Z 1Y6; berringe@ interchange.ubc.ca 